\title{
ETIKA JURNALISTIK DALAM PROSES PELIPUTAN BERITA
}

\author{
Fanny Lesmana \\ Program Studi Ilmu Komunikasi, Fakultas Ilmu Komunikasi, Universitas Kristen Petra \\ Jl. Siwalankerto 121-131, Surabaya 60236, INDONESIA \\ e-mail: flesmana@petra.ac.id
}

\begin{abstract}
Salah satu kegiatan yang dilakukan oleh jurnalis dalam menjalankan profesinya adalah meliput berita. Dalam proses peliputan berita yang dilakukan melalui inisiatif pribadi, penugasan dari redaktur maupun undangan berupa konferensi pers dan press release, jurnalis sangat rawan dari keadaan untuk tidak patuh pada kode etik profesi yang disandangnya. Ketaatan terhadap Kode Etik Jurnalistik merupakan hal yang patut dilakukan oleh jurnalis di Indonesia. Namun, latar belakang pendidikan atau profesi, sikap atau kepercayaan yang dianut dan faktor materialistik, serta masalah kecepatan membuat jurnalis tidak mudah untuk menaati Kode Etik Jurnalistik meskipun hal tersebut sangat terkait dengan tanggung jawab moral sang jurnalis dan kredibilitas media massa dimana jurnalis bernaung. Rekomendasi yang bisa disampaikan dari simpulan adalah perlu dikedepankan sebuah ketegasan dari perusahaan pers dalam pola merekrut jurnalis, melakukan pelatihan serta menanamkan idealisme pada diri jurnalis dalam mengemban Kode Etik Jurnalistik, khususnya dalam proses peliputan berita
\end{abstract}

Keywords: etika jurnalistik, peliputan berita, jurnalis.

\begin{abstract}
ABSTRAK
One of the activities carried out by journalists in their profession is covering the story. In the process of news reporting is done through personal initiative, assignment editors and invitations in the form of press conferences and press releases, journalists extremely vulnerable from the state to not abide by the code of professional conduct bears. Adherence to the Kode Etik Jurnalistik is a thing that should be done by journalists in Indonesia. However, educational or professional background, attitudes or beliefs held and meterialistik factors, as well as the speed issue makes a journalist is not easy to adhere to the Code of Ethics of Journalism although it is strongly associated with the moral responsibility of the journalist and the credibility of the media where journalists take shelter. Therefore, the company needs a firmness of the press in the pattern of recruiting journalists, conducting the training, and put the ideals on themselves journalists when they carry out the Kode Etik Jurnalistik, in particular in the process of news coverage.
\end{abstract}

Kata kunci: journalism ethics, news gathering, journalist.

\section{PENDAHULUAN}

Fenomena peliputan dalam pemberitaan hilangnya pesawat AirAsia QZ 8501 pada 28 Desember 2014 sangat menarik perhatian khalayak, khususnya netizen. Rifai Pamone, salah seorang jurnalis stasiun televisi MetroTV dianggap tidak memiliki empati saat mewawancarai keluarga penumpang pesawat QZ 8501 tersebut (Arifiani, 2014, par. 1).

Meski tidak ada aduan maupun sanksi secara langsung dari Dewan Pers, namun apa yang dilakukan oleh jurnalis Metro TV ini bisa saja dianggap kurang profesional dalam menjalankan tugas peliputan. Ketidakprofesionalan ini dianggap melanggar pasal 2 Kode Etik Jurnalistik.

Melihat fenomena ini, tampaklah etika merupakan hal yang sangat signifikan dalam proses peliputan sebuah peristiwa. Hal ini terbukti dari cukup banyaknya kecaman yang disampaikan oleh khalayak luas, khususnya para netizen seperti yang ada di bawah ini (Dermawan, 2014).

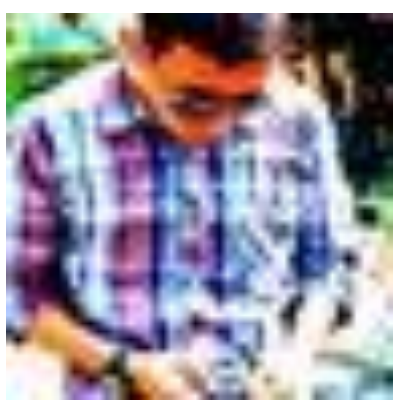

Ini Ito@callysta_chicko

@Metro_TV buat wartawan metro,please deh,itu keluarga korban airasia lagi panik malah ditanya2,liat donk situasinya...

11.29 - 28 Des 2014 


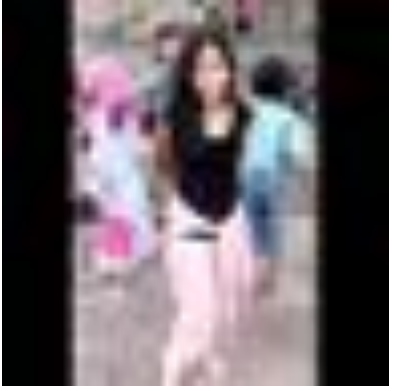

-Sweet Alien @fiorenza_nad

You should think before you ask@rifaipamone we name it "kode etik jurnalistik" . Do you have it?

11.54 - 28 Des 2014

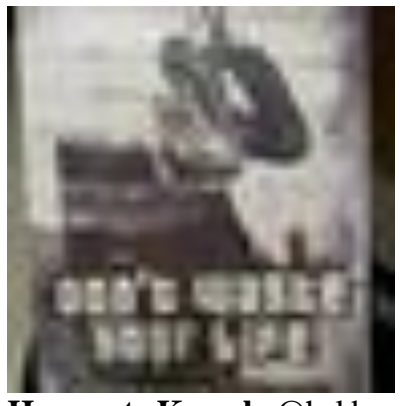

Hermanto Kumala @hekbuzz

@Metro_TV, wartawan anda seharusnya punya empati utk tidak terus mengejar pertanyaan pada keluarga korban air asia Qz8501

11.25 - 28 Des 2014

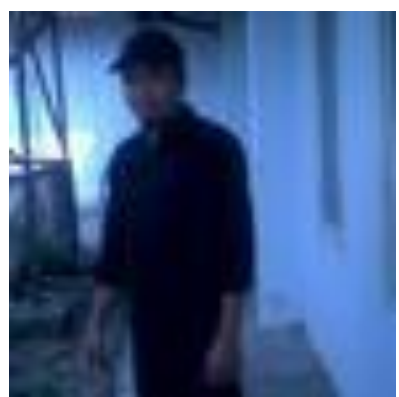

Raffi Mds

@kroya_mds

Wartawan metrotv yg mencecar pertanyaan kpd keluarga korban AirAsia, mohon segera ditindak diberi sanksi!!! Tidak punya etika!!!

Etika - dalam Kamus Besar Bahasa Indonesia (1999) - dirumuskan dalam tiga pengertian, yakni ilmu tentang apa yang baik dan buruk; kumpulan asas atau nilai yang berkenaan dengan akhlak; serta nilai mengenai benar dan salah yang dianut oleh masyarakat kita. Meski demikian, Romo Frans MagnisSuseno (dalam Sobur, 2001) menegaskan bahwa etika tidak secara langsung membuat kita menjadi manusia yang lebih baik. Karenanya, etika juga perlu dibiasakan pada setiap anggota masyarakat, tidak hanya pada kehidupannya pribadi melainkan juga pada saat menjalankan profesinya.
Dalam menjalankan profesi apapun, etika juga merupakan hal yang penting. Karenanya, pada beberapa profesi, telah dikenakan kode etik profesi yang secara otomatis menjadi patokan dasar bagi kaum profesional itu untuk menjalankan profesinya. Jurnalis sangat terikat dengan pelaksanaan etika profesinya karena etika berfungi menjaga para pelaku profesi - dalam hal ini jurnalis - tetap berkomitmen untuk menjaga pranata sosial dalam lingkungannya (Sobur, 2001). Hal ini berarti, seorang jurnalis dalam menjalankan pekerjaannya tidak bisa bertindak semaunya sendiri, melainkan perlu menjaga keseimbangan, yakni bertanggung jawab tatkala menjalankan kebebasannya dalam berekspresi (Libois, dalam Haryatmoko, 2007). Memang etika dalam perspektif profesi apapun bukanlah aturan yang dilegalisasi. Kekuatan berlakunya tidak diatur oleh pembuat undang-undang, melainkan tergantung pada orang yang mengemban profesi tersebut (Mulkan, 2011).

Jurnalis atau wartawan memiliki kesempatan yang besar untuk memaparkan informasi melalui media massa sekaligus dapat memberikan pengaruh yang besar bagi pembacanya. Subjektivitas jurnalis acapkali tidak dapat dihindari saat membagi informasinya melalui media massa. Itu sebabnya, mematuhi kode etik profesi sangat penting untuk menjaga agar jurnalis tidak menjadi bias dalam penyampaian informasi. Selain itu, jurnalis atau dalam hal ini perusahaan media yang tidak memegang teguh Kode Etik Jurnalistik dalam menjalankan kinerjanya dapat membuat masyarakat kehilangan kepercayaan pada informasi yang disampaikan. Hal ini terkait dengan bisnis maupun idealisme.

Secara bisnis, jika masyakarat tidak percaya pada sebuah perusahaan media, maka media dapat kehilangan pembaca atau pelanggan. Kepatuhan jurnalis pada Kode Etik Jurnalistik akan memberikan tingkat ketepercayaan media massa pada masyarakat. Secara idealisme, perusahaan media yang jurnalisnya melanggar Kode Etik Jurnalistik akan kehilangan fungsi kontrol sosialnya. Padaha ciri khas dari sebuah media massa adalah fungsi kontrol sosial (Lesmana, 2010).

Bagir Manan, Ketua Dewan Pers, dalam Peringatan Hari Pers Nasional tahun 2015 menegaskan, pers (jurnalis) sebaiknya tidak hanya memberi perhatian pada persoalan hukum belaka, melainkan juga mengarahkan diri dengan memberi perhatian besar pada persoalan terhadap ketaatan pada kode etik, peningkatan profesionalisme serta tradisi demokrasi (Buletin Etika, Februari 2015). Hal ini menunjukkan bahwa persoalan menjaga etika profesi di kalangan jurnalis masih menjadi hal yang sangat penting. 
Pada bulan Oktober 2014 telah terbukti adanya pelanggaran yang dilakukan oleh jurnalis dalam hal peliputan sebuah pemberitaan, yakni terkait dengan pembelian saham PT. Krakatau Steel. Keempat jurnalis - dari Metro TV, Harian Seputar Indonesia, Harian Kompas dan situs berita detikcom, dinyatakan oleh Dewan Pers telah menyalahgunakan profesinya dalam peliputan isu saham perdana PT. Krakatau Steel. Keempat jurnalis tersebut terbukti menggunakan identitasnya sebagai wartawan untuk memperoleh hak istimewa pembelian saham perdana PT. Krakatau Steel (tempo.co, 1 Desember 2010).

Dewan Pers sesuai Pernyataan Penilaian dan Rekomendasi (PPR Nomor 27A/PPR-DP/XII/2014 tentang Pengaduan Renep Indrawan terhadap Harian Radar Bojonegoro memutuskan bahwa media cetak tersebut dinyatakan melanggar Pasal 1 Kode Etik Jurnalistik karena meskipun jurnalis telah melakukan upaya konfirmasi pada Renep indrawan, namun upaya itu dianggap belum cukup dalam memenuhi prinsip keberimbangan (Dewan Pers, 2015).

Di Indonesia, kode etik profesi yang dipegang oleh para jurnalis di Indonesia secara umum adalah Kode Etik Jurnalistik yang ditetapkan oleh Dewan Pers melalui Peraturan Dewan Pers No. 6/PeraturanDP/V/2008 tentang Pengesahan Surat Keputusan Dewan Pers Nomor 03/SK-DP/III/2006 tentang Kode Etik Jurnalistik Sebagai Peraturan Dewan Pers di Jakarta pada 14 Maret 2006. Kode etik ini berisi 11 pasal.

- Pasal 1: Wartawan Indonesia bersikap independen, menghasilkan berita yang akurat, berimbang, dan tidak beritikad buruk

- Pasal 2: Wartawan Indonesia menempuh caracara yang profesional dalam melaksanakan tugas jurnalistik.

- Pasal 3: Wartawan Indonesia selalu menguji informasi, memberitakan secara berimbang, tidak mencampurkan fakta dan opini yang menghakimi, serta menerapkan asas praduga tak bersalah.

- Pasal 4: Wartawan Indonesia tidak membuat berita bohong, fitnah, sadis, dan cabul.

- Pasal 5: Wartawan Indonesia tidak menyebut-kan dan menyiarkan identitas korban kejahatan susila dan tidak menyebut-kan identitas anak yang menjadi pelaku kejahatan.

- Pasal 6: Wartawan Indonesia tidak menyalahgunakan profesi dan tidak menerima suap.

- Pasal 7: Wartawan Indonesia memiliki hak tolak untuk melindungi narasumber yang tidak bersedia diketahui identitas maupun keberadaannya, menghargai ketentuan embargo, informasi latar belakang, dan "off the record" sesuai dengan kesepakatan.
- Pasal 8: Wartawan Indonesia tidak menulis atau menyiarkan berita berdasarkan prasangka atau diskriminasi terhadap seseorang atas dasar perbedaan suku, ras, warna kulit, agama, jenis kelamin, dan bahasa serta tidak merendahkan martabat orang lemah, miskin, sakit, cacat jiwa, atau cacat jasmani.

- Pasal 9: Wartawan Indonesia menghormati hak narasumber tentang kehidupan pribadinya, kecuali untuk kepentingan publik.

- Pasal 10: Wartawan Indonesia segera mencabut, meralat, dan memperbaiki berita yang keliru dan tidak akurat disertai dengan permintaan maaf kepada pembaca, pendengar, atau pemirsa.

- Pasal 11: Wartawan Indonesia melayani hak jawab dan hak koreksi secara proposional.

Selain KEJ, jurnalis masih terikat pula dengan kode etik atau aturan perilaku yang dijalankan oleh setiap perusahaan media tempat mereka bernaung. Misalnya, Harian Jawa Pos membuat peraturan tertulis yang dimuat di halaman 2 surat kabar cetak, yakni Wartawan Jawa Pos dilarang menerima uang maupun barang dari sumber berita. Demikian pula Harian Media Indonesia yang memuat aturan tertulis di halaman 6 versi cetak, yaitu: Dalam melaksanakan tugas jurnalistik, wartawan Media Indonesia dilengkapi kartu pers dan tidak diperkenankan menerima atau meminta imbalan dengan alasan apa pun. Stasiun televisi Metro TV juga memasang pengumuman serupa dalam running text di layar televisi.

Dalam konteks pelanggaran Kode Etik Jurnalistik yang dilakukan oleh jurnalis, maka Dewan Pers lah yang memberikan penilaian akhir. Namun, yang memberikan sanksi kepada jurnalis bukanlah Dewan Pers, melainkan dilakukan oleh organisasi wartawan maupun perusahaan media.

\section{PEMBAHASAN}

Peliputan berita merupakan salah satu tugas utama jurnalis atau wartawan dalam menjalankan profesinya. Rolnicki (2008) menyebutkan, selama tahap pencarian fakta, jurnalis (wartawan) juga membutuhkan etika personal dan profesional. Di Indonesia, jurnalis terikat pada Kode Etik Jurnalistik seperti yang telah disebut pada baian Pendahuluan. Namun, masih tak terhindarkan bahwa kriteria dan standar profesi yang diisyaratkan dalam KEJ tidak dipatuhi dan tidak dilaksanakan. (Luwarso, $2003: 2$ ).

Sobur (2001) menjelaskan, yang dimaksud dengan kode etika adalah tuntunan atau pedoman moral bagi sebuah profesi yang disusun oleh para anggota profesi itu sendiri. Selanjutnya, anggota profesi tersebut 
terikat dalam mempraktikkan kode etika itu. Artinya, jurnalis di Indonesia terikat dalam mempraktikkan Kode Etik Jurnalistik, tanpa terkecuali dan tanpa alasan apa pun. Pelanggaran terhadap Kode Etika Jurnalistik akan berakibat sanksi moral pada jurnalis.

Ada tiga cara bagi seorang jurnalis dalam mencari atau meliput sebuah berita. Pertama, jurnalis berinisiatif sendiri untuk mencari informasi. Kedua, jurnalis mendapatkan penugasan dari redaktur. Ketiga, jurnalis mendapat undangan dalam bentuk konferensi pers maupun mendapat sumber informasi berupa press release.

Terkait dengan etika dalam menjalankan profesi, jurnalis cukup rawan untuk mengabaikan etika profesi pada ketiga cara di atas, khususnya ketika mengumpulkan berita melalui konperensi pers.

Dalam kasus yang menimpa empat jurnalis dalam pembelian saham perdana PT. Krakatau Steel sangat dimungkinkan hal itu terjadi karena kedekatan jurnalis dengan pihak perusahaan lantaran seringnya memperoleh undangan konperensi pers. Meski tidak ditegaskan secara langsung dalam penjelasan kejadian tersebut, namun keberadaan jurnalis yang sangat dekat dengan subjek pemberitaan sangat memungkinkan terjadinya penyimpangan dalam pelaksanaan profesi jurnalistik.

Konperensi pers tentu bukanlah hal yang diharamkan dalam proses peliputan berita. Namun, secara etika, lobang untuk pelanggaran yang dilakukan oleh jurnalis, cukup besar.

Dalam buku Emka (2007), Anshari Thayib - seorang jurnalis senior- menceritakan tentang seorang kawannya yang menghadiri sebuah konperensi pers. Setelah menulis berita itu, ia berangkat ke luar negeri karena mendapatkan tugas dari kantor. Pulang ke tanah air, ia diberi tahu isterinya bahwa kantor tempatnya bekerja ribut besar karena ia dituduh menerima amplop dan tidak melaporkan amplop tersebut. Bingung karena merasa tidak menerima amplop, ia membongkar sebuah amplop besar yang diletakkan di meja kerjanya. Di dalam amplop besar itu, ia menemukan sebuah amplop lain (yang ukurannya lebih kecil, namun tebal). Ia langsung membuat surat pengunduran diri tanpa membuka amplop itu. Inilah keterkaitan erat antara profesionalisme dan integritas.

Jurnalis memang perlu dekat dengan narasumber agar lebih mudah dan cepat dalam menggali informasi. Namun, kedekatan dengan narasumber dapat berakibat pada tidak objektifnya jurnalis dalam memandang suatu peristiwa. Budaya sungkan acap- kali menjadi pembenaran atas ketidakobjektifan jurnalis dalam menjalankan profesinya. Bisa saja jurnalisnya yang sungkan sehingga pemberitaan tidak objektif, atau bisa saja perusahaannya yang sungkan sehingga enggan menolak ketidakprofesionalan jurnalis seperti yang terjadi pada proses pembeloan saham PT. Krakatau Steel.

Dalam bukunya Mediating The Message, Shoemaker dan Reese (1996) menuliskan seorang jurnalis memiliki potensi untuk memberikan pengaruh terhadap isi pesan dalam sebuah media. Ada tiga faktor yang memengaruhi kondisi ini, yaitu latar belakang profesional sang jurnalis (misalnya saja latar belakang pendidikan); sikap, nilai, dan kepercayaan yang dipegang oleh jurnalis sebagai individu; dan orientasi profesi dari jurnalis itu.

Dalam hubungannya dengan masalah latar belakang profesional, pelanggaran KEJ pada proses pencarian berita terjadi karena masih banyak jurnalis yang tidak memahami bahkan tidak mengetahui adanya KEJ. Tidak semua perusahaan media massa (pers) memperkenalkan KEJ pada jurnalisnya, khususnya jurnalis yang baru bergabung. Di sisi lain, KEJ merupakan hal yang sangat signifikan bagi jurnalis dalam menjalankan proses peliputan berita. Emka (2005) menceritakan adanya seorang wartawan muda yang dengan jujur mengakui bahwa ia belum pernah membaca KEJ.

Lalu, bagaimana seorang jurnalis dapat mengetahui serta menerapkan KEJ? Belajar pada bidang studi ilmu komunikasi, khususnya pada penjurusan jurnalistik, sudah pasti akan memberikan bekal pengetahuan dan penerapan tentang KEJ.

Tentu saja hal ini juga tidak menjamin bahwa seorang jurnalis yang lulus dari bidang studi ilmu komunikasi atau jurnalistik pasti akan menerapkan KEJ dalam bekerja. Di sisi lain, seorang jurnalis tidak dapat dituntut untuk selalu berasal dari latar belakang ilmu komunikasi ataupun ilmu jurnalistik agar ia dapat mengetahui dan menerapkan KEJ dalam bekerja. Hal lebih penting adalah bagaimana seorang jurnalis mau mendalami profesinya sehingga tak segan untuk mengedepankan KEJ sebagai kode etik profesinya. Selain itu, perusahaan pers juga perlu menunjukkan perihal KEJ sebagai standar kinerja jurnalis, baik pada saat perekrutan jurnalis baru maupun saat bekerja sehari-hari.

Hal kedua terkait dengan sikap, nilai dan kepercayaan yang dianut oleh jurnalis. Dalam sebuah penelitian, Lesmana (2010) mendapati ada seorang jurnalis perempuan yang menolak diberi amplop oleh narasumbernya dengan alasan ketentraman hati. 
Perempuan berjilbab ini mengaku menolak amplop bukan sekadar mematuhi kode etik, melainkan demi ketentraman hatinya. Meski demikian, ia juga mengaku pernah menerima amplop dari narasumbernya. Namun, setelah itu ia menyerahkan amplop yang masih utuh itu ke sekretaris redaksi untuk dikembalikan pada narasumber. Memang tidak mudah untuk langsung menolak amplop dari narasumber yang mungkin saja dapat menyinggung perasaan pemberi. Bisa juga hal ini dimaksudkan untuk 'menyelamatkan diri' jurnalis dari cercaan para jurnalis lain yang menerima amplop tersebut.

Masih bersinggungan dengan masalah nilai dan kepercayaan yang dipegang oleh seorang jurnalis. Sebuah koran lokal di Jawa Timur pernah memuat sebuah berita dengan judul "Tak Mau Dipotret, Takut Anaknya Dikeluarkan dari Sekolah". Meski judulnya demikian, namun berita tersebut tetap dihiasi dengan foto tersangka yang menjadi narasumber. Syah (2011) menegaskan seharusnya media massa yang bersangkutan mematuhi permintaan narasumber, namun pers seolah-olah tidak peduli dengan permintaan itu. Hal ini merupakan pelanggaran dari pasal $7 \mathrm{KEJ}$ yang berbicara tentang off the record. Seharusnya jurnalis mematuhi perjanjian tersebut. Namun, sepertinya jurnalis mengorbankan sikap yang seharusnya menjadi idealisme dalam menjalankan proses pencarian berita.

Terkait dengan proses peliputan yang dilakukan oleh Rifai Pamone pada keluarga penumpang Air Asia QZ 8501, penulis mengamati adanya keseriusan jurnalis dalam mencari informasi namun melupakan adanya hal yang disebut empati. Ini sangat terkait dengan sikap jurnalis dalam berhubungan dengan narasumber. Jurnalis perlu menjadi profesional dalam menjalankan tugasnya, termasuk dalam memahami kesukaran maupun kesedihan yang sedang dirasakan oleh narasumber.

Hal ketiga, terkait masalah materialistik. Buletin Etika edisi Desember 2009 memuat pernyataan Wikrama Iryans Abidin (Anggota Dewan Pers masa bakti 2007-2010) terkait dengan profesionalisme jurnalis dalam menjalankan profesinya. Ia mengatakan:

"Banyak yang terlibat dalam profesi ini datang dengan itikad, value yang berbeda. Mungkin di antaranya banyak yang masuk wartawan hanya karena faktor materialistik, bukan untuk hal yang lebih substansial seperti untuk mengembangkan demokrasi."

Perkara faktor materialistik sepertinya memang bukan perkara baru dalam dunia profesi jurnalis. Alasan gaji jurnalis yang kecil acap mewarnai pelanggaran etika jurnalis. Tim AJI (Aliansi Jurnalis Independen) Surabaya pernah merilis sebuah buku berjudul “Amplop Candu Bagi Jurnalis' (2001). Buku ini menyebutkan bahwa hampir sebagian besar jurnalis di kota Surabaya pernah menerima pemberian amplop dari narasumber. Gaji kecil serta tidak adanya larangan tegas dari perusahaan media tempat mereka bekerja, menjadi alasan pembenaran hal yang melanggar etika tersebut.

Saat Lesmana (2010) mewawancarai Kukuh, mantan Ketua AJI Surabaya terkait kepatuhan jurnalis anggota AJI terhadap kode etik, ia menyebutkan adanya jurnalis anggota AJI yang mengundurkan diri dari AJI dengan alasan tidak bisa menolak amplop. Padahal, jika menelisik isi dari KEJ pasal 6, dengan tegas dikatakan bahwa jurnalis tidak boleh menyalahgunakan profesi dan menerima suap.

Perihal menerima suap (amplop) ini kemudian ditunjukkan oleh Kovach dan Rosenstiel (dalam Ishwara, 2005) sebagai hal yang membatasi jurnalis dari kebebasan yang seharusnya menjadi syarat dasar jurnalisme. Menerima amplop (suap) saat proses peliputan berita dapat membuat jurnalis menjadi tidak netral dalam menyampaikan informasi. Jurnalis tidak lagi bebas dalam menyampaikan informasi yang akurat dan jujur.

Ada faktor keempat yang dapat membuat seorang jurnalis gagal dalam menerapkan KEJ saat menelisik informasi berita. Faktor itu disebut kecepatan.

Strentz (1993) menyatakan berita memiliki rentang hidup yang singkat. Karenanya, media massa berusaha menyampaikan informasi sesegera mungkin kepada khalayaknya. Tapi, hal ini juga memberikan celah bagi jurnalis dalam pengumpulan fakta di lapangan.

Ketika terjadi peristiwa kerusuhan di Banjarmasin saat Pemilu 1997, penulis yang saat itu masih aktif menjadi jurnalis dan berdomisili di Surabaya mendapatkan tugas untuk menggali informasi. Karena sulitnya jalur transportasi, maka penulis mencari informasi melalui telepon pada narasumber yang dikenal. Narasumber tersebut mengatakan bahwa ada seorang tokoh agama yang diserang massa hingga terluka parah. Narasumber juga menceritakan beberapa hal lain yang cukup detail.

Karena merasa telah memperoleh informasi yang cukup, maka penulis mengemas informasi tersebut dan melaporkannya dalam bentuk berita. Penulis tidak melakukan verifikasi sama sekali karena memercayai narasumber ini. 
Setelah berita dimuat, penulis mendapatkan informasi bahwa tokoh agama tersebut tidak mengalami luka parah, meski memang benar perihal informasi serangan massa ke rumahnya.

Tentu saja hal ini membuat penulis kehilangan kredibilitas karena dapat dianggap menyebarkan berita bohong. Penulis mendapatkan teguran lisan dari pimpinan, juga mendapatkan pertanyaan dari beberapa tokoh masyarakat yang mengenal penulis perihal informasi yang terlanjut dimuat itu.

Kesalahan fatal itu tidak berujung pada pemecatan karena perusahaan media tempat penulis bernaung melihat adanya unsur ketidaksengajaan dalam hal tersebut. Meski demikian, penulis belajar banyak dari peristiwa itu serta bersyukur hanya mendapat teguran saja. Luwarso (2003) menyebutkan bahwa sah saja bagi perusahaan pers untuk memberikan sanksi bagi jurnalis yang mengabaikan profesionalisme jurnalis dengan cara memberikan teguran, skorsing hingga pemecatan (Luwarso, 2003)

Penulis - sebagai jurnalis - seharusnya melakukan verifikasi saat menghimpun data-data untuk berita yang ditulisnya. Namun, karena penulis merasa adanya tuntutan kecepatan dalam menyampaikan informasi ini, maka penulis tidak lagi melakukan verifikasi pada sumber-sumber lainnya.

Kecepatan seolah telah menjadi dewa bagi media massa. Padahal, contoh di atas terjadi pada saat media cetak belum mendapatkan persaingan kecepatan dari media daring seperti saat ini. Dapat dibayangkan, pada tahun-tahun belakangan ini, saat media daring menjadi raja atas media, faktor kecepatan menjadi sesuatu yang lebih penting lagi.

Kovach dan Rosenstiel (2001) menekankan bahwa intisari jurnalisme adalah disiplin verifikasi. Tanpa menguji atau memeriksa kembali sebuah informasi yang didapatkan, maka jurnalis dapat dikatakan telah melanggar KEJ pasal 3 serta pasal 4 karena dapat dianggap telah membuat berita bohong.

Dalam kasus Harian Radar Bojonegoro yang diadukan oleh Renep Indrawan pada Dewan Pers (dewan Pers, 2015) terbukti bahwa jurnalis Harian Radar Bojonegoro terbukti telah melakukan konfirmasi perihal pemberitaannya namun upaya tersebut dianggap belum memenuhi prinsip keberimbangan. Situasi ini dapat terjadi bila kecepatan menjadi segalagalanya bagi media massa.

Permasalahan ketaatan terhadap kode etik profesi jurnalistik tidak hanya menjadi permasalahan di Indonesia. Di Amerika Serikat, kode etik untuk jur- nalis juga sangat dijunjung tinggi. Secara umum, kode etik yang dikenal dengan nama Society of Professional Journalits memberikan saran eksplisit yang mewajibkan jurnalis untuk menguji akurasi informasi dari narasumber serta berlatih dengan hati-hati untuk menghindari kesalahan yang tidak disengaja. Di sisi lain, kesalahan yang disengaja tentu saja tidak dapat dimaafkan (Meyer, 2004).

Pelanggaran KEJ yang dilakukan oleh jurnalis dalam proses peliputan berita dapat sangat merugikan kedua belah pihak, baik jurnalis itu sendiri maupun masyarakat. Emka (2007) menjelaskan bahwa keberadaan kode etik sangat terkait pada warga masyarakat sebagai narasumber maupun sebagai penerima informasi, melainkan juga dapat menghalangi hak jurnalis dalam proses memperoleh, mengolah dan menyiarkan informasi. Rivers dan Mathews (1994) menegaskan, "Pers yang etis adalah yang memberikan informasi dan fakta yang benar dari berbagai sumber sehingga para pembaca bisa menilai sendiri informasi tersebut".

\section{KESIMPULAN}

Kode etik merupakan hal yang perlu dikedepankan oleh seorang jurnalis dalam menjalankan pekerjaannya, karena hal ini akan memberikan kebebasan pada jurnalis agar dapat bersikap netral dan jujur.

Namun dalam menjalankan profesinya - khususnya dalam hal peliputan berita - jurnalis terkendala dalam menerapkan KEJ sebagai landasan profesinya. Beberapa faktor yang dapat menjadi hambatan dalam menjalankan KEJ adalah latar belakang pendidikan atau profesi, sikap atau kepercayaan yang dianut dan faktor meterialistik, serta masalah kecepatan.

Perusahaan media massa atau pers perlu lebih ketat dalam melakukan proses perekrutan jurnalis setidaknya mempertanyakan pemahaman jurnalis perihal KEJ serta memberikan pelatihan kepada jurnalis, termasuk dalam hal menunjukkan keberadaan KEJ sebagai landasan profesi.

Perusahaan pers dapat dikatakan sebagai pihak yang bertanggung jawab untu meningkatkan dan menjaga profesionalisme dalam medianya, termasuk memberikan sanksi kepada jurnalis yang melanggar profesionalismenya. Empat perusahaan media yang jurnalisnya terlibat dalam pembelian saham PT Krakatau Steel telah memberikan sanksi sepatutnya kepada jurnalis yang bersangkutan. Dua di antaranya - jurnalis detikcom dan jurnalis Harian Seputar Indonesia - mengundurkan diri dari perusahaan media tempat mereka bernaung. 
Selain itu, jurnalis sendiri perlu mengedepankan keinginan untuk mendalami profesinya di dalam memiliki nilai-nilai hidup yang selaras dengan KEJ; serta menanamkan idealisme agar tidak terkontaminasi dengan pelanggaran KEJ, khususnya dalam proses peliputan berita.

\section{DAFTAR REFERENSI}

Arifiani, Septina. 2014. Paksa Keluarga Korban Wawancar, Wartawan Metro TV Dikecam. http://semarang.solopos.com/2014/12/28/pesaw at-airasia-hilang-paksa-keluarga-korbanwawancara-wartawan-metro-tv-dikecam563314, diakses tanggal 21 Juni 2015.

Buletin Etika edisi Desember 2009. 70 Persen Wartawan Tidak Profesional.

Buletin Etika edisi Februari 2015. Ketua Dewan Pers, Bagir Manan: Kemerdekaan Pers Bukan Tanpa Batas.

Dermawan, Alan. 2014. Paksa Keluarga Korban Air Asia, Wawancara Wartawan Metro TV Diprotes. http://boomee.co/2014/12/paksa-keluargakorban-airasia-wawancara-wartawan-metrotv-diprotes, diakses tanggal 21 Juni 2015.

Dewan Pers. 2015. http://www.dewanpers.or.id/ page/ pengaduan/pprasio/?id=2174, diakses tanggal 21 Juni 2015.

Emka, Zainal Arifin. 2005. Wartawan Juga Bisa Salah: Etika Pers dalam Terapan. Surabaya: JP Books.

--_-_. 2007. Wartawan Seharusnya Tepercaya. Surabaya: Alfina Primatama.

Haryatmoko. 2007. Etika Komunikasi: Manipulasi Media, Kekerasan dan Pornografi. Yogyakarta: Kanisius.

Ishwara, Luwi. 2005. Catatan-catatan Jurnalisme Dasar. Jakarta: Kompas.
Kovach, Bill \& Rosenstiel, Tom. 2001. Sembilan Elemen Jurnalisme. Jakarta: Pantau.

Lesmana, Fanny. 2010. Tesis: Praktik Peliputan Jurnalis dan Aplikasi Kode Etik Wartawan (KEWI) dalam Kampanye Pemilukada Kota Surabaya 2010.

Meyer, Philip. 2004. The Vanishing Newspaper: Saving Journalism in the Information Age. Columbia: University of Missouri Press.

Mulkan, Dede. 2011. Matinya Kode Etik Jurnalistik: Berdasarkan Studi Kasus di Metro TV dan TV One. Bandung: Arsad Press.

Rivers, William L. dan Cleve Mathews. 1994. Etika Media Massa dan Kecenderungan untuk Melanggarnya. Jakarta: PT Gramedia Pustaka Utama.

Rolnicki, dkk. 2008. Pengantar Dasar Jurnalisme edisi kesebelas. Jakarta. Kencana.

Shoemaker, Pamela. J. \& Stephen D. Reese. 1996. Mediating the Message $2^{\text {nd }}$ edition. USA: Longman Publisher.

Sobur, Alex. 2001. Etika Pers: Profesionalisme Dengan Nurani. Bandung: Humaniora Utama Press.

Strentz, Herbert. 1993. Reporter dan Sumber Berita. Jakarta: Gramedia.

Syah, Sirikit. 2011. Rambu-rambu Jurnalistik: Dari Undang-Undang hingga Hati Nurani. Yogyakarta: Pustaka Pelajar.

Tempo.co. 2010. http://nasional.tempo.co/read/news/ 2010/12/01/173296013/inilah-keputusan-dewanpers-soal-skandal-saham-krakatau-steel-itu, diakses tanggal 21 Juni 2015.

Tim AJI Surabaya. 2001. Amplop Candu Bagi Jurnalis. Surabaya. AJI Surabaya. 